Geology, Geophysics \& Environment • 2012 • Vol. 38 • No. 4 • 427-438

http://dx.doi.org/10.7494/geol.2012.38.4.427

\title{
AQUEOUS CADMIUM \\ REMOVAL BY HYDROXYLAPATITE AND FLUOROAPATITE
}

\author{
Jakub MATUSIK, Tomasz BAJDA \& Maciej MANECKI \\ AGH University of Science and Technology, Faculty of Geology, \\ Geophysics and Environmental Protection; \\ al. Mickiewicza 30, 30-059 Krakow, Poland; \\ e-mail:jakub_matusik@wp.pl,bajda@geol.agh.edu.pl,gpmmanec@cyf-kr.edu.pl
}

\begin{abstract}
Reducing the bioavailability of toxic heavy metals in groundwaters and urban soils by phosphate addition is an effective technique described in the literature. It is based on the reaction between metal ions and phosphates and results in the precipitation of metal substituted phosphate phases. The formed phosphates are highly insoluble and thermodynamically stable over almost entire $\mathrm{pH}$ and Eh range. In the presented study the efficiency and mechanism of cadmium uptake by synthetic hydroxylapatite and natural fluoroapatite was examined within the $\mathrm{pH}$ range of 3-7 for different reaction times (2-1440 hours). The solids after reactions were characterized by XRD and SEM-EDS. Percentage reduction of cadmium concentration in the experiments with fluoroapatite and hydroxylapatite, regardless of $\mathrm{pH}$, did not exceed $17 \%$ and $25 \%$, respectively. Cadmium uptake from the solution mainly resulted from the formation of cadmium phosphates and/or Ca-Cd phosphate solid solutions on the apatites surface. The release rate of phosphate ions by hydroxylapatite was relatively high. This promoted crystallization of a large number of small crystals. In turn dissolution of fluoroapatite was slower and thus the formation of large crystals was observed. There was no clear evidence for cadmium-calcium ion-exchange mechanism.
\end{abstract}

Key words: $\mathrm{Ca}-\mathrm{Cd}$ phosphate, mineral dissolution, immobilization

\section{INTRODUCTION}

Cadmium is a highly toxic element contaminating natural waters and soils. The main sources of this metal pollutant are mining and smelting, industrial wastes, sewage sludge and atmospheric deposition (Adriano 2001). Harmful $\mathrm{Cd}$ ions assimilated in excessive amounts may be hazardous to living matter (Flick et al. 1971). Accumulation of cadmium in human organism leads to serious health problems such as kidney disfunction, hypertension and osteoporosis (Kabata-Pendias \& Pendias 1993). 
Last decades show that amount of bioavailable cadmium in the soil environment continuously increses (Alloway 1995). Equilibria in water and soil solutions are mainly controlled by sorption/desorption and crystallization/dissolution processes. Therefore a promising way of eliminating mobile metals from soils is to convert them into stable metal phosphates by addition of soluble or insoluble phosphates (Levi Minzi \& Petruzzelli 1984, Ma et al. 1993, Ruby et al. 1994, Xu \& Schwartz 1994, Ma et al. 1995, Cotter-Howells 1996, Lambert et al. 1997, Zhang et al. 1997, Fedoroff et al. 1999, Shashkova et al. 1999, Manecki et al. 2000b, Basta et al. 2001, McGowen et al. 2001, McGrellis et al. 2001, Lusvardi et al. 2002, Basta McGowen 2004, Lundager et al. 2004, Raicevic et al. 2005, Manecki et al. 2006, Marchat et al. 2007, Matusik et al. 2008). This method, which is well known in the literature as in situ phosphate formation has convincing advantages. Among a variety of suggested decontamination techniques it is relatively cheap and environmentally attractive due to the fact that toxic ions can be neutralized without the need for soil removal. Although total amount of cadmium in soil remains unchanged, the formed waste phosphate solid is essentially harmless for living organisms due to its low solubility and high stability in broad $\mathrm{pH}$ and Eh range (Nriagu 1984). Other proposed technologies usually require removal of polluted soils, which is expensive and destructive for the environment.

The literature devoted to this subject focuses mainly on the interaction of cadmium with hydroxylapatite revealing many new details (Fedoroff et al. 1999, McGrellis et al. 2001, Lusvardi et al. 2002, Lundager et al. 2004, Raicevic et al. 2005, Marchat et al. 2007). However information about fixation of cadmium by fluorapatite particles is scattered and uncomplete.

The purpose of this research was to compare the effectiveness of aqueous cadmium removal by synthetic hydroxylapatite and natural fluorapatite. Additionally new information about cadmium fixation mechanism by apatites, in particular fluorapatite, was obtained.

\section{MATERIALS AND METHODS}

\section{Materials}

All experiments were conducted in $0.5 \mathrm{~L}$ polypropylene bottles. Re-distilled water and analitycal-reagent grade chemicals were used throughout. Synthetic hydroxyapatite (HAP) from Biorad Laboratories Hercules, California, USA and natural fluoroapatite (FAP) from Perth of Wilberforce, Ontario, Canada were used. Complete descriptions of the HAP are provided by Xu Schwartz (1994) and Lower et al. (1998). The FAP was obtained from the rock collection of the School of Natural Resources, Ohio State University; its detailed characteristics were published by Manecki et al. (2000a).

\section{Batch experiments}

The initial concentration of $\mathrm{Cd}(\mathrm{II})=4.80 \mathrm{mM}$ dictated by previous experiments (Matusik et al. 2008) was chosen for all experiments. The initial concentrations of $\mathrm{Cd}(\mathrm{II})$ and $\mathrm{PO}_{4}$ 
ions, $4.80 \mathrm{mM}$ and $3.52 \mathrm{mM}$ respectively, were constant through all experiments and resulted from the stoichiometry of expected product - cadmium phosphate $\mathrm{Cd}_{3}\left(\mathrm{PO}_{4}\right)_{2}$. Each of batch experiments with HAP and FAP consisted of two sets: a control set and an experimental set. The control set was designed to measure the amount of phosphates released to solution via minerals dissolution. Therefore, $300 \mathrm{mg}$ of solid was added to $500 \mathrm{~mL}$ of re-distilled water. In the experimental set the same portion of solid was added to a $500 \mathrm{~mL}$ solution containing cadmium $([\mathrm{Cd}]=4.80 \mathrm{mM})$ in the form of nitrate. The $\mathrm{pH}$ both in control and in experimental set was adjusted before solid addition to initial values of 3,5, and 7 using $0.01 \mathrm{M}$ potassium hydroxide and $0.01 \mathrm{M}$ nitric acid solutions. No attempt was made to maintain the $\mathrm{pH}$ constant during the experiments. Solution samples $(5 \mathrm{~mL})$ were collected from both sets after 2, 6, 24, 48, 168, 336, 720, 1080, 1440 hours. They were filtered and analyzed for $\mathrm{pH}, \mathrm{PO}_{4}$ (control set) and $\mathrm{pH}, \mathrm{Cd}, \mathrm{PO}_{4}$ (experimental set). After two months the solids were filtered, washed on the filter with re-distilled water and acetone, dried in $105^{\circ} \mathrm{C}$, and analyzed by XRD and SEM-EDS.

\section{Analitycal methods}

The concentration of Cd(II) was measured using Philips PU 9100X atomic absorption spectrometer (AAS). Total dissolved phosphate was determined colorimetrically according to the molybdenum blue method (Lenoble et al. 2003) with the use of Carl Zeiss Jena SPEKOL ZV UV-Visible spectrophotometer. For the $\mathrm{pH}$ measurements an ELMETRON CPI 501 meter and a glass electrode were used.

Powder XRD patterns of the samples were recorded using Philips APD PW 3020 $X^{\prime}$ Pert diffraction camera with Ni-filtered $\mathrm{Cu}-\mathrm{K} \alpha$ radiation in the range of $2 \theta=2-73^{\circ}$ with constant step equal to 0.05 . The unit cell parameters were calculated using DHN/PDS (DHN-Powder Diffraction System) software package and refined by least squares method. Quartz was used as an internal standard. Morphology observations and elemental analyses of the prepared samples were performed using FEI QUANTA 200 field emission scanning electron microscope coupled with EDS system (SEM-EDS). Samples were analyzed without prior coating.

\section{RESULTS AND DISCUSSION}

\section{Apatites dissolution}

Figure 1 shows the changes of phosphate concentration and $\mathrm{pH}$ with time during apatites dissolution. The dissolution patterns for the HAP and FAP are comparable which suggests similar dissolution mechanism. For apatites a polynuclear surface mechanism was proposed (Christoffersen et al. 1996). Moreover, surface controlled dissolution connected with the formation of etch pits and sharp edges was reported by Manecki et al. (2000b) for chlorapatite. 


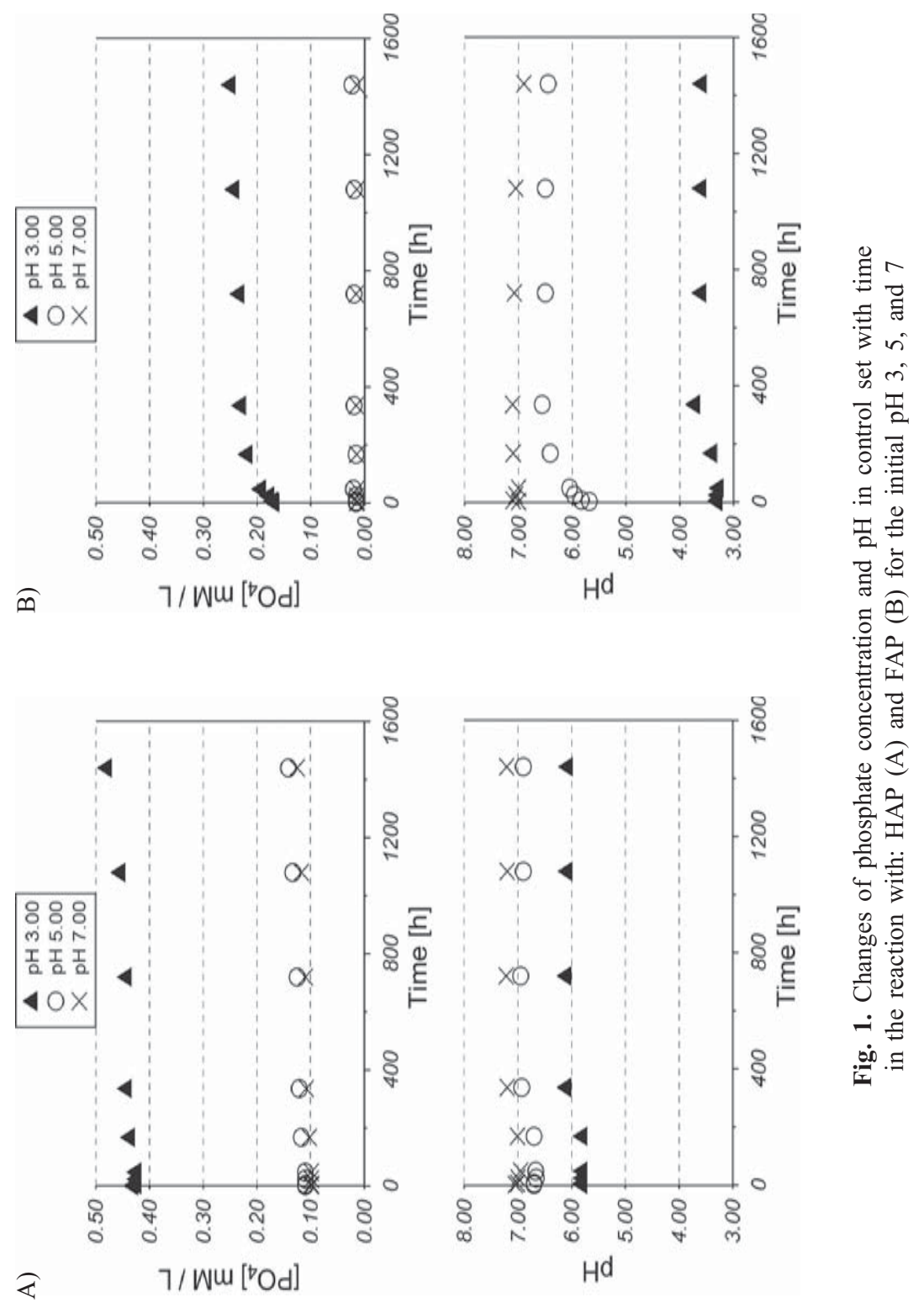


For both minerals a parabolic phase of dissolution, which is characteristic for batch experiments, was observed. Rapid dissolution during first few hours may be related to the presence of fine particles or inhomogeneities on the apatites surface (Berner 1981). Smith et al. (1977) suggested that this dissolution behavior is a property of apatite minerals. After 24 hours the phosphate release rate decreased.

The final concentration of phosphates, regardless of the initial $\mathrm{pH}$, was higher for the HAP. After two months (1440 hours) concentration of phosphates in control set was the highest for the initial $\mathrm{pH} 3$ and equl to $0.48 \mathrm{mM} / \mathrm{L}$. It was lower for the initial $\mathrm{pH} 5$ and 7 where it was equal to $0.14 \mathrm{mM} / \mathrm{L}$ and $0.12 \mathrm{mM} / \mathrm{L}$, respectively. The amount of phosphates released by the FAP was significantly lower. The phosphate concentrations, for the initial $\mathrm{pH} \mathrm{3,} \mathrm{5,} \mathrm{and} \mathrm{7,} \mathrm{reached} 0.25 \mathrm{mM} / \mathrm{L}, 0.02 \mathrm{mM} / \mathrm{L}$ and $0.01 \mathrm{mM} / \mathrm{L}$, respectively. For both apatites the amount of released phosphate was the highest for the initial $\mathrm{pH} 3$. This confirms that the apatite solubility increases with decreasing $\mathrm{pH}$ (Chien et al. 1975, Arends et al. 1987, Narasaraju et al. 1971, Narasaraju \& Phebe 1996). The higher solubility of the HAP as compared to the FAP is caused by the difference in solubility products $\left(\mathrm{K}_{\mathrm{SP}}\right)$ of the minerals which are equal to $10^{-58.23}$ and $10^{-59.56}$, respectively (Lindsay 1979).

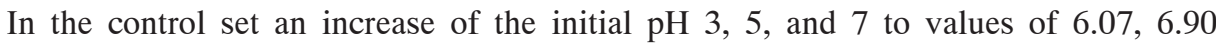
and 7.21, respectively was noticed for the reactions with HAP. In turn, in the experiment with FAP the initial $\mathrm{pH}$ values increased to 3.59, 6.45 and 6.90, respectively. Changes of the $\mathrm{pH}$ may be explained by the uptake or release of $\mathrm{H}^{+}$ions during formation of various phosphate anion species: $\mathrm{HPO}_{4}{ }^{2-}, \mathrm{H}_{2} \mathrm{PO}_{4}{ }^{-}$and $\mathrm{H}_{3} \mathrm{PO}_{4}{ }^{0}$ (Manecki et al. 2000b).

\section{Cadmium immobilization by apatites}

Figure 2 shows changes of cadmium concentration and $\mathrm{pH}$ with time in experimental sets for the HAP and the FAP. Cadmium fixation rates are considerably varying in time. For the both apatites in the first few hours immoblization rate is very high and then it slightly decreases. This is in agreement with literature (Marchat et al. 2007). The cadmium concentration equilibrium was not achieved even after 2 months of the reaction which was also reported by Fedoroff et al. (1999).

It was noticed that the initial concentration of cadmium $4.80 \mathrm{mM} / \mathrm{L}$ at the end of the experiment, regardless of $\mathrm{pH}$, was lowest in the experiments with the HAP. For the initial

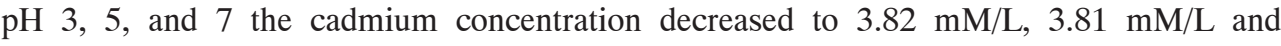
$3.63 \mathrm{mM} / \mathrm{L}$, respectively. The total amount of cadmium removed from the solution in the reactions with the FAP was lower than in the case of the HAP. The initial cadmium concentration for initial $\mathrm{pH} \mathrm{3,5}$, and 7 decreased to $4.08 \mathrm{mM} / \mathrm{L}, 4.00 \mathrm{mM} / \mathrm{L}$ and $4.10 \mathrm{mM} / \mathrm{L}$, respectively. It seems that the efficiency of cadmium removal in batch experiments is low comparing with "slow introduction" experiments peformed by McGrellis et al. (2001). The decrease of cadmium concentration in the applied experimental conditions mainly results from the formation of cadmium phosphates or calcium-cadmium phosphates on the surface of apatites as described below. 


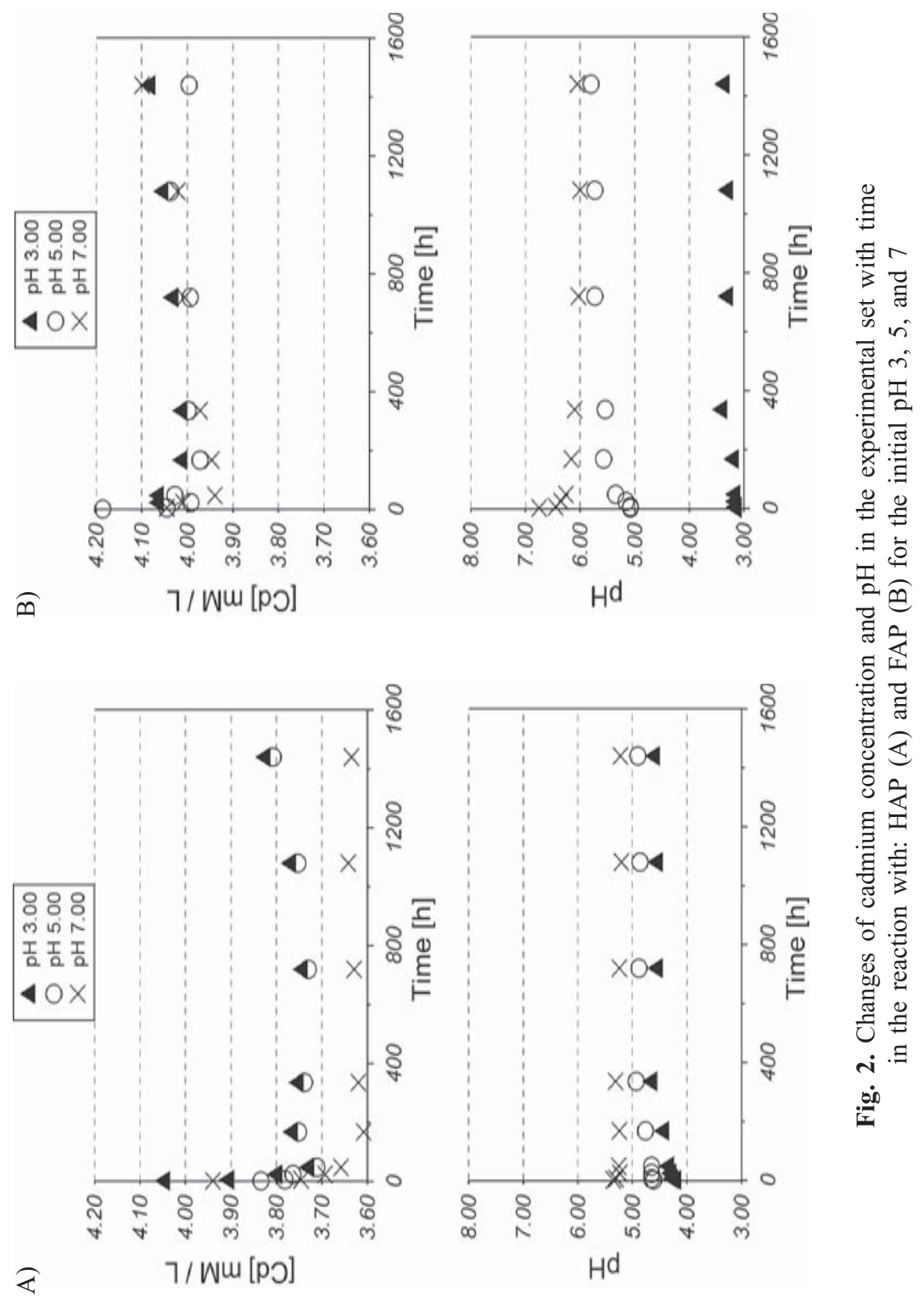


The $\mathrm{pH}$ changes in the experimental set for the HAP were observed, initial $\mathrm{pH} 3$ increased to a value of 4.59, while initial $\mathrm{pH} 5$ and 7 decreased to 4.90 and 5.22, respectively. In the reaction with the FAP the $\mathrm{pH}$ was equal to $3.36,5.80$ and 6.05 , respectively.

\section{Solid characterization}

\section{XRD analyses}

The XRD patterns of HAP and FAP obtained before and after reaction with cadmium regardless of the initial $\mathrm{pH}$ do not show significant changes (data not shown). The absence of additional peaks suggests that new crystalline phases were not formed or only a small amount of amorphous precipitate is present. However the amount of new crystalline phase may be below detection of the XRD. Peak positions and their shapes are very similar which indicates that structural perturbations did not take place. Calculated lattice constants of the pure HAP: $a=9.426 \AA ; c=6.883 \AA$ and the FAP: $a=9.385 \AA ; c=6.885 \AA$ are in good agreement with parameters given by the ICCD database: $a=9.418 \AA ; c=6.884 \AA$ and $a=9.378 \AA ; c=6.883 \AA$, respectively.

\section{SEM analyses}

Figures 3 and 4 show the surface of the HAP and the FAP after reaction with cadmium, respectively. It is well established in literature that cadmium uptake by HAP is a result of adsorption of cadmium on apatite surface followed by ion exchange with calcium (Jeanjean et al. 1996, McGrellis et al. 2001, Lusvardi et al. 2002, Marchat et al. 2007). However, our results show direct evidence of dissolution-precipitation mechanism for both minerals. Such behaviour, that is dissolution of mineral and subsequent formation of new precipitate, was observed in reactions of synthetic HAP with lead (Ma et al. 1993, Lower et al. 1998, Manecki et al. 2000a).
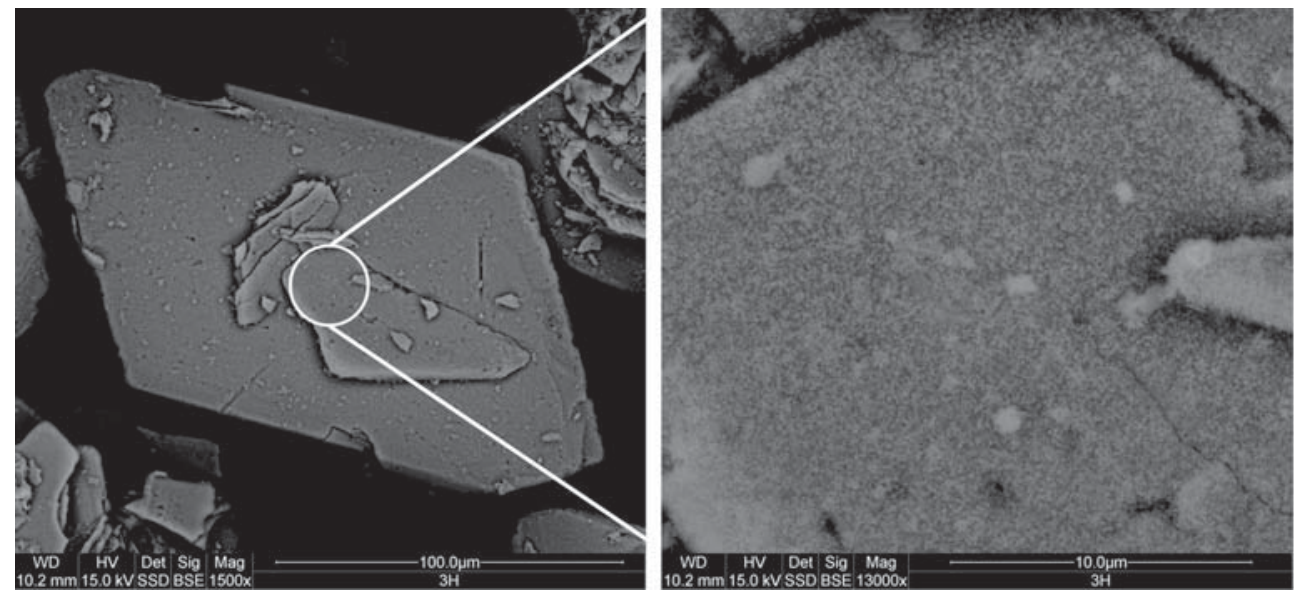

Fig. 3. SEM microphotograph of HAP after reactions with cadmium 
A)

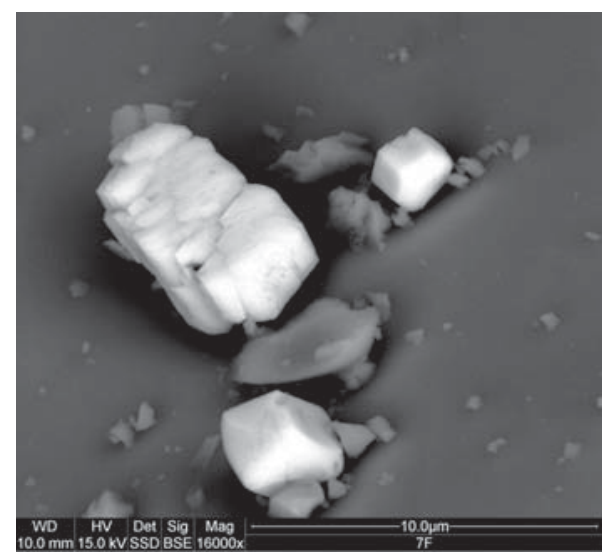

B)

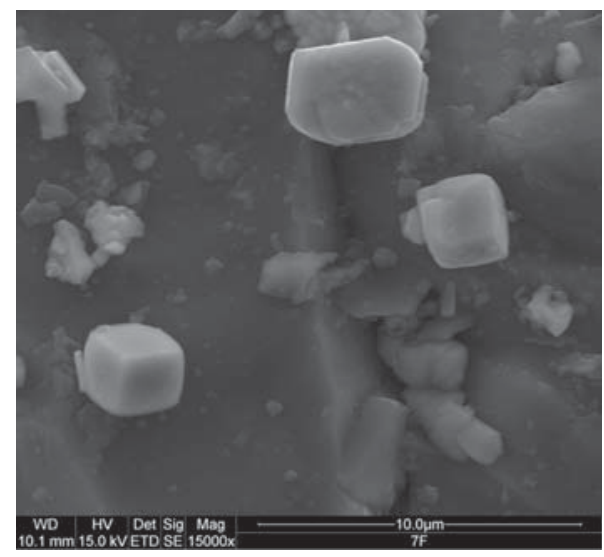

Fig. 4. SEM microphotographs of FAP after reactions with cadmium:

A) BSE image; B) SE image

Although XRD patterns did not reveal formation of new phases after reaction with cadmium, the SEM observations clearly show their occurence. Various size and character of the formed precipitates may be related to different dissolution behaviour of apatites. The HAP releases the phosphate ions faster and this promotes formation of a large number of small precipitates, which uniformly cover the whole mineral surface (Fig. 3). Probably these precipitates are amorphous, which was also reported by Lusvardi et al. (2002). The EDS analyses of the HAP surface indicate the same chemical composition in every measured point (Fig. 5A). This confirms that particles are surrounded by a new precipitate, which is characterized by constant cadmium content. In turn the FAP releases the phosphate ions slower and in this way enables formation of relatively large crystals (Fig. 4). The observed phases are well developed and faces and edges may be clearly seen in many of them (Fig. 4B). High cadmium content for these phases was noticed (Fig. 5B). This clearly suggests crystallization of cadmium hydrogenophosphates on the FAP surface. The type of mechanism responsible for cadmium uptake by apatites is controlled by $\mathrm{pH}$ and the initial cadmium concentration. 
A)

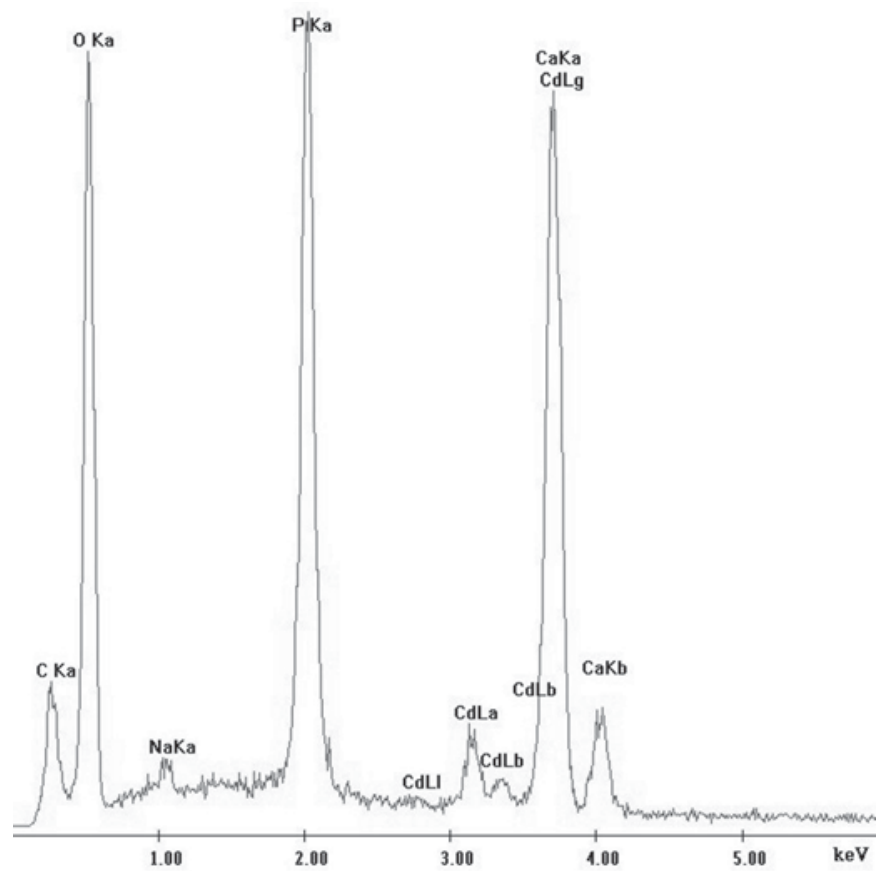

B)

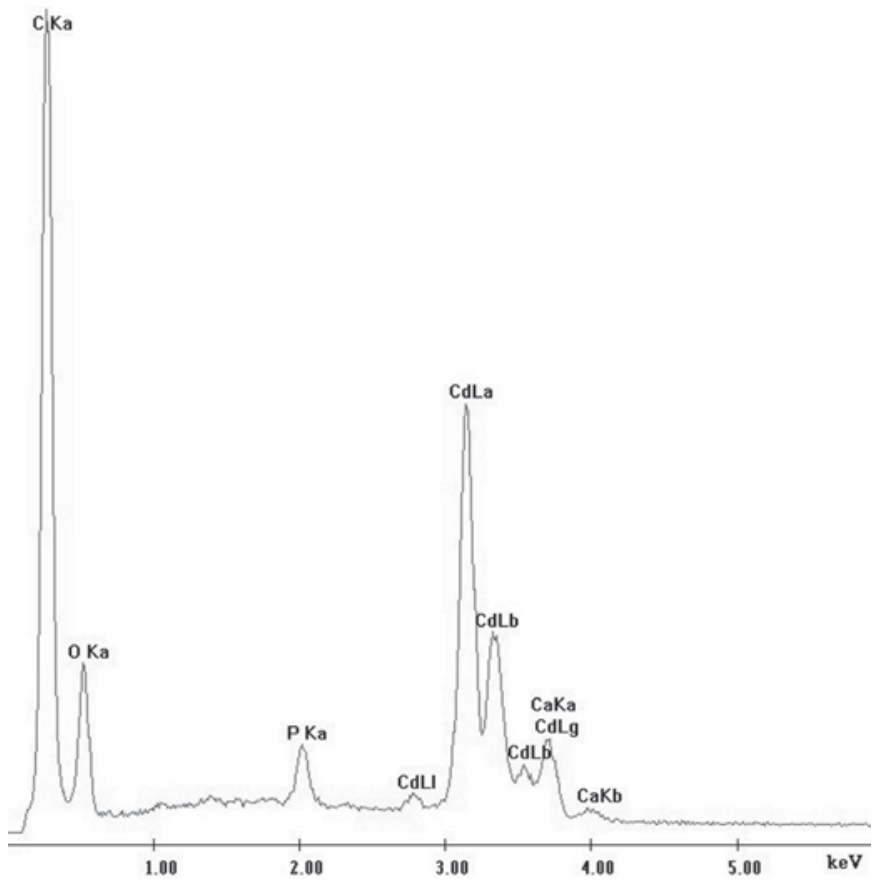

Fig. 5. EDS analysis of: A) HAP surface; B) crystal formed on the FAP surface 


\section{CONCLUSIONS}

The presented study confirms the capability of apatites to immobilize aqueous cadmium ions and provides new data affecting conditions for cadmium fixation by HAP and FAP. In addition new information concerning uptake mechanism are shown.

It was noticed that after two months cadmium uptake in the reactions with HAP, regardless of $\mathrm{pH}$, was higher than in experiments with FAP. The percentage removal of cadmium in the experiments with HAP for the initial $\mathrm{pH} 3,5$, and 7 was equal to respectively $20.6 \%$, $21.0 \%$ and $24.5 \%$. In turn in the reactions with FAP it was calculated to $15.2 \%, 17.0 \%$ and $14.9 \%$ for the same $\mathrm{pH}$, respectively.

Cadmium uptake in the applied experimental conditions resulted mainly from formation of new solids on the apatites surface. The nature of precipitates is strongly associated with the dissolution behaviour of apatites. Fast release of phosphate ions by the HAP promotes formation of a large number of small precipitates, which cover the mineral surface. In turn, the FAP slowly releases phosphate ions and thus enables formation of relatively large crystals. Generally cadmium has the tendency to form own phosphates and/or calcium-cadmium solid solutions. There is no clear evidence for ion-exchange mechanism.

The research was financed by the AGH University of Science and Technology statutory grant.

\section{REFERENCES}

Adriano D.C., 2001. Trace Elements in Terrestrial Environments: Biogeochemistry, Bioavailability and Risks of Metals. Springer, New York.

Alloway B.J., 1995. Heavy Metals in Soils. Blackie Academic and Professional, Glasgow, UK.

Arends J.A., Christoffersen J., Christoffersen M.R., Eckert H., Fowler B.O., Heughebaert J.C., Nancollas G.H., Yesinowski J.P. \& Zawacki S.J., 1987. A calcium hydroxylapatite precipitated from an aqueous solution. Journal of Crystal Growth, 84, 515-532.

Basta N.T., Gradwohl R., Snethen K.L. \& Schroder J.L., 2001. Chemical immobilization of lead, zinc and cadmium in smelter-contaminated soils using biosolids and rock phosphate. Journal of Environmental Quality, 30, 1222-1230.

Basta N.T. \& McGowen S.L., 2004. Evaluation of chemical immobilization treatments for reducing heavy metal transport in a smelter-contaminated soil. Environmental Pollution, 127, 73-82.

Berner R.A., 1981. Kinetics of weathering and diagenesis. Reviews in Mineralogy, 8, 69-110.

Chien S.H., Wier D.R. \& Black C.A., 1975. Supersaturation phenomena and the formation of fluorapatite in aqueous suspensions of phosphate rock. Soil Science Society of America Proceedings, 39, 43-47. 
Christoffersen J., Christoffersen M.R. \& Johansen T., 1996. Kinetics of growth and dissolution of fluorapatite. Journal of Crystal Growth, 163, 295-303.

Cotter-Howells J., 1996. Lead phosphate formation in soils. Environmental Pollution, 93, 9-16.

Fedoroff M., Jeanjean J., Rouchaud J.C. \& Mazerolles L., 1999. Sorption kinetics and diffusion of cadmium in calcium hydroxyapatites. Solid State Science, 1, 71-84.

Flick D.F., Kray Bill H.F. \& Dimitroff J.M., 1971. Toxic effects of cadmium: a review. Environmental Research, 4, 71-85.

Jeanjean J., McGrellis S., Rouchaud J.C., Fedoroff M., Rondeau A., Perocheau S. \& Dubis A., 1996. A crystallographic study of the sorption of cadmium on calcium hydroxyapatites: Incidence of cationic vacancies. Journal of Solid State Chemistry, 126, 195-201.

Kabata-Pendias A. \& Pendias H., 1993. Biogeochemia pierwiastków śladowych. Wydawnictwo Naukowe PWN, Warszawa.

Lambert M., Pierzynski G., Erickson L. \& Schnoor J., 1997. Remediation of lead-, zincand cadmium contaminated soils. Issues in Environmental Science and Technology, 7, 91-102.

Lenoble V., Deluchat V., Serpaud B., \& Bollinger J.C., 2003. Arsenite oxidation and arsenate determination by the molybdene blue method. Talanta, 61, 267-276.

Levi-Minzi R. \& Petruzzelli G., 1984. The influence of phosphate fertilizers on Cd solubility in soil. Water Air Soil Pollution, 23, 423-429.

Lindsay W.L., 1979. Chemical equilibria in soils. John Wiley \& Sons. New York.

Lower S.K., Maurice P.A. \& Traina S.J., 1998. Simultaneous dissolution of hydroxylapatite and precipitation of hydroxylpyromorphite: direct evidence of homogeneous nucleation. Geochimica et Cosmochimica Acta, 62, 1773-1780.

Lundager Madsen H.E., Abbona Y. \& Barrese E. 2004. Effects of cadmium on crystallization of calcium phosphates. Crystal Research and Technology, 39, 235-239.

Lusvardi G., Malavasi G., Menabue L. \& Saladini M., 2002. Removal of cadmium ions by means of cadmium hydroxyapatite. Waste Management, 22, 853-857.

McGrellis S., Serafini J.N., Jeanjean J., Pastol J.L. \& Fedoroff M., 2001. Influence of the sorption protocol on the uptake of cadmium ions in calcium hydroxyapatite. Separation and Purification Technology, 24, 129-138.

Ma Q.Y., Logan T.J. \& Traina S.J., 1995. Lead immobilization from aqueous solutions and contaminated soils using phosphate rocks. Environmental Science and Technology, 29, 1118-1126.

Ma Q.Y., Traina S.J., Logan T.J. \& Ryan J.A., 1993. In situ lead immobilization by apatite. Environmental Science and Technology, 27, 1803-1810.

Manecki M., Bogucka A., Bajda T., Borkiewicz O., 2006. Decrease of Pb bioavailability in soils by addition of phosphate ions. Environmental Chemistry Letters, 3, 178-181.

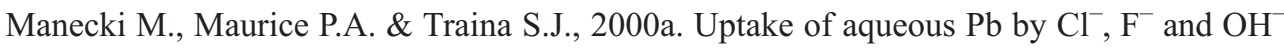
apatites: Mineralogic evidence for nucleation mechanisms. American Mineralogist, 85, 932-942. 
Manecki M., Maurice P.A. \& Traina S.J., 2000b. Kinetics of aqueous Pb reaction with apatites. Soil Science, 165, 920-933.

Marchat D., Bernache-Assollant D. \& Champion E., 2007. Cadmium fixation by synthetic hydroxyapatite in aqueous solution - Thermal behaviour. Journal of Hazardous Materials, A139, 453-460.

Matusik J., Bajda T. \& Manecki M., 2008. Immoblization of aqueous cadmium by addtion of phosphates. Journal of Hazardous Materials, 152, 1332-1339.

McGowen S.L., Basta N.T. \& Brown G.O., 2001. Use of diammonium phosphate to reduce heavy metal solubility and transport in smelter-contaminated soil. Journal of Environmental Quality, 30, 493-500.

Narasaraju T.S.B., Chickerur N.S. \& Singh R.P., 1971. pH-dependence of solubilities of solid solutions of calcium and strontium hydroxylapatites. Journal of Inorganic \& Nuclear Chemistry, 33, 3194-3197.

Narasaraju T.S.B. \& Phebe D.E., 1996. Some physico-chemical aspects of hydroxylapatite. Journal of Materials Science, 31, 1-21.

Nriagu J.O., 1984. Formation and stability of base metal phosphates in soils and sediments. [in:] Nriagu J.O. \& Moore P.B. (eds), Phosphate Minerals, Springer-Verlag, London, 318-329.

Raicevic S., Kaludjerovic-Radoicic T. \& Zouboulis A.I., 2005. In situ stabilization of toxic metals in polluted soils using phosphates: theoretical prediction and experimental verification. Journal of Hazardous Materials, B117, 41-53.

Ruby M.V., Davis A. \& Nicholson A., 1994. In situ formation of lead phosphates in soil as a method to immobilize lead. Environmental Science and Technology, 28, 646-654.

Shashkova I.L., Rat'ko A.I. \& Kitikova N.V., 1990. Removal of heavy metal ions from aqueous solutions by alkaline-earth metal phosphates. Colloid Surface, A160, 207215.

Smith A.N, Posner A.M. \& Quirk J.P., 1977. A model describing the kinetics of dissolution of hydroxylapatite. Journal of Colloid Interface Science, 62, 475-494.

Xu Y., \& Schwartz F.W., 1994. Lead immobilization by hydroxyapatite in aqueous solutions. Journal of Contaminant Hydrology, 15, 187-206.

Zhang P.C., Ryan J.A. \& Bryndzia L.T., 1997. Pyromorphite formation from goethite adsorbed lead. Environmental Science and Technology, 31, 2673-2678. 